\title{
MULHERES VÍTIMAS DE VIOLÊNCIA: UMA REVISÃO INTEGRATIVA ${ }^{1}$ WOMEN VICTIM OF VIOLENCE: AN INTEGRATIVE REVIEW
}

\author{
Letícia Chagas² e Martha Helena Teixeira de Souza $^{3}$
}

\section{RESUMO}

A violência contra as mulheres é caracterizada como um ato violento baseado no gênero. No Brasil, diariamente milhares de mulheres sofrem algum tipo de violência, ocasionando sofrimento físico, sexual ou psicológico, e, muitas vezes, a morte. Diante dessa problemática, realizamos uma revisão integrativa, com objetivo de identificar nos artigos pesquisados os principais agressores, serviços e cuidados destinados às mulheres vítimas de violências. A partir da análise, concluiu-se que o cuidado às mulheres vítimas de violência é fragmentado, seguindo uma lógica de hegemonia médica, por isso, para que haja integralidade no cuidado é preciso atendimento multiprofissional, considerando a demanda da mulher vítima de violência. Assim como as mulheres, os agressores também necessitam de acompanhamento, uma vez que tem um vínculo afetivo com a vítima, visando a prevenção da reincidência.

Palavras-chave: Gênero, Políticas Públicas, Saúde Mental.

\section{ABSTRACT}

The violence against women is characterized as a violent act based in gender. In Brazil, thousands of women are daily suffering some kind of violence, occasioned by physical injured, sexual or physiological, many times, death. Facing this problem, we made an integrative review with the goal of identify in researched articles of the main aggressors to the women victims of violence. From the analysis, we concluded that care about women victim of violence is fragmented, following a logic of medical hegemony, therefore, that there is integrality in care is needed multi-professional support considering the demand of woman victim of violence. As well as women, the aggressors also need support, since they have affective bond with the victim, aiming the prevention of recurrence.

Keywords: gender, public policy, mental health.

\footnotetext{
${ }^{1}$ Trabalho de Conclusão de Especialização em Rede de Atenção Integrada em Saúde Mental - Universidade Franciscana - UFN.

${ }^{2}$ Psicóloga, especialista em Rede de Atenção Integrada em Saúde Mental - Universidade Franciscana - UFN. E-mail: cchagasleticia@gmail.com

${ }_{3}^{3}$ Orientadora. Docente da Universidade Franciscana - UFN. E-mail: marthahts@gmail.com.
} 


\section{INTRODUÇÃO}

$\mathrm{Na}$ atual conjuntura de políticas públicas, segurança e saúde, a violência de gênero é considerada um problema social grave. Assim, é concebida como uma violação dos direitos humanos. A violência contra a mulher é caracterizada como um ato violento baseado no gênero, podendo ocasionar sofrimento físico, sexual ou psicológico e, muitas vezes, até provocar a morte. A palavra gênero abrange intersecções, compreendendo raça, classe, etnia, entre outras modalidades.

Na última década do século XX, a promulgação da Constituição de 1988 incidiu na inclusão de mais direitos para as mulheres. Além de prever igualdade de gênero, a Constituição também instituiu o Sistema Único de Saúde (SUS). Todavia, somente em 2004, através da mobilização do movimento de mulheres e feministas, instituiu-se a Política Nacional de Atenção Integral à Saúde da Mulher (PNAISM).

Outros dois marcos significativos para as mulheres foram a promulgação da Lei Maria da Penha (Lei 11.340/06) e, a recente Lei do feminicídio (Lei 13.140/15). Contudo, apesar das importantes conquistas, os dados estatísticos do DataSenado (2013) apontam que 700 mil brasileiras continuam sendo alvo de agressões, em que Brasil se encontra em $7^{\circ}$ lugar num ranking de 84 países. Ordenados segundo a taxa de feminicídios, esses dados confirmam que as mulheres ainda sofrem com a herança social do machismo.

Nesse contexto, as violências ocorrem de forma diferente para homens e mulheres. A violência de gênero influencia diretamente na subjetividade das mulheres, sendo um problema social e de saúde pública. Diante desse cenário, foi desenvolvido um estudo tendo como objetivo: identificar nos artigos pesquisados os principais agressores, serviços e cuidados destinados às mulheres vítimas de violências. Para concretizar, nessa pesquisa, buscamos na literatura nacional, mediante uma revisão integrativa, produções que abordam violência e saúde mental das mulheres.

\section{MATERIAL E MÉTODOS}

Este artigo consiste em uma revisão integrativa, a qual possibilita "a construção de uma análise ampla da literatura, contribuindo para discussões sobre métodos e resultados de pesquisas, assim como reflexões sobre a realização de futuros estudos" (MENDES; SILVEIRA; GALVÃO, 2008, p. 760).

Seguindo a revisão integrativa, percorremos as seguintes etapas: 1) estabelecimento do tema de interesse; 2) busca dos artigos na base de dados, através dos descritores; 3) leitura minuciosa dos artigos selecionados, identificando as informações a serem extraídas; 4) interpretação dos resultados, análise e discussão dos dados e, por fim, 5) apresentação a revisão/síntese do conhecimento.

A busca dos artigos foi realizada na base de dados LILACS, incluindo artigos de todos os anos, utilizando os descritores: "saúde mental", "mulheres" e "violência", os quais foram utilizados como disparadores para a discussão ao longo do texto. Foram incluídos somente artigos completos, em português, 
que se referiam a mulheres e à violência. Após a apuração das produções, de acordo com o critério de seleção, realizou-se a leitura detalhada dos artigos, extraindo informações relevantes para essa pesquisa. Por fim, interpretamos os resultados e apresentamos a revisão/síntese.

\section{RESULTADOS}

A busca na base de dados resultou em 36 artigos, 13 atenderam aos critérios de inclusão. Não atendendo o critério de inclusão tivemos: 9 publicações, que não eram artigos; 1 artigo completo que não estava disponível; 1 que não se referia à violência; 1 que não tinha o foco nas mulheres; 1 artigo estava duplicado; 7 não estavam disponíveis no idioma português; 3 não mencionavam as mulheres, totalizando em 23 artigos descartados. No Quadro 1 são apresentados os artigos selecionados.

Quadro 1 - Artigos encontrados a partir da busca em base de dados (LILACS).

\begin{tabular}{|c|c|c|c|c|c|}
\hline & $\begin{array}{c}\text { Título/Periódico/ } \\
\text { Ano }\end{array}$ & Autores & Objetivo & Metodologia & Principais Resultados \\
\hline $\mathbf{A}$ & $\begin{array}{l}\text { Abuso de álcool e } \\
\text { drogas e violência } \\
\text { contra as mulhe- } \\
\text { res: denúncias de } \\
\text { vividos. } \\
\text { Revista Brasileira } \\
\text { de Enfermagem, } \\
2014 .\end{array}$ & $\begin{array}{l}\text { VIEIRA, L. B; } \\
\text { CORTES, L. F.; } \\
\text { PADOIN, S.M. M.; } \\
\text { SOUZA, I. E. de } \\
\text { O.; PAULA, C. C., } \\
\text { TERRA, M. G. }\end{array}$ & $\begin{array}{l}\text { Analisar a inter- } \\
\text { face entre o uso } \\
\text { abusivo de álcool e } \\
\text { outras drogas pelos } \\
\text { companheiros e o } \\
\text { vivido de mulheres } \\
\text { que denunciam } \\
\text { situações de vio- } \\
\text { lência. }\end{array}$ & $\begin{array}{l}\text { Estudo qualitati- } \\
\text { vo. Releitura em } \\
\text { banco de dados da } \\
\text { pesquisa. }\end{array}$ & $\begin{array}{l}\text { Ações do companheiro como uso } \\
\text { abusivo de álcool e/ou drogas, ciúmes } \\
\text { e relações extraconjugais dificultaram } \\
\text { o convívio. Os atos violentos foram } \\
\text { agressões físicas, verbais, psicológicas, } \\
\text { sexuais e ameaças de morte. Aponta-se } \\
\text { a importância de desenvolver nos es- } \\
\text { paços de educação em saúde, junto aos } \\
\text { usuários de serviços de saúde mental, } \\
\text { junto aos homens, para desconstrução } \\
\text { da cultura machista. }\end{array}$ \\
\hline B & $\begin{array}{l}\text { Análise do ciclo da } \\
\text { violência doméstica } \\
\text { contra a mulher. } \\
\text { Journal of Human } \\
\text { Growth and } \\
\text { Development, } 2016 .\end{array}$ & $\begin{array}{l}\text { LUCENA, K. D. T.; } \\
\text { DEININGER, L. S. C.; } \\
\text { COELHO, H. F. C.; } \\
\text { MONTEIRO, A. C. C.; } \\
\text { VIANNA, R. P. T.; } \\
\text { NASCIMENTO, J. A }\end{array}$ & $\begin{array}{l}\text { Analisar o ciclo da } \\
\text { violência doméstica } \\
\text { contra a mulher. }\end{array}$ & $\begin{array}{l}\text { Inquérito de base } \\
\text { populacional, trans- } \\
\text { versal, exploratório, } \\
\text { descritivo de abor- } \\
\text { dagem quantitativa. } \\
\text { Análise descritiva. }\end{array}$ & $\begin{array}{l}\text { No âmbito da assistência à saúde, é } \\
\text { necessário qualificar os profissionais } \\
\text { na perspectiva de gênero, bem como } \\
\text { suporte de conhecimento teórico aos } \\
\text { profissionais de saúde envolvidos na } \\
\text { assistência à saúde das vítimas de } \\
\text { violência. }\end{array}$ \\
\hline $\mathrm{C}$ & $\begin{array}{l}\text { Articular saúde } \\
\text { mental e relações } \\
\text { de gênero: dar voz } \\
\text { aos sujeitos silen- } \\
\text { ciados. } \\
\text { Ciência \& Saúde } \\
\text { Coletiva, } \\
2009 .\end{array}$ & $\begin{array}{l}\text { SANTOS, A. M. } \\
\text { C. C. }\end{array}$ & $\begin{array}{l}\text { Analisar a expe- } \\
\text { riência do sofri- } \\
\text { mento psíquico a } \\
\text { partir de relatos de } \\
\text { homens e mulheres } \\
\text { usuários de serviço } \\
\text { público de saúde. }\end{array}$ & $\begin{array}{l}\text { Pesquisa qualita- } \\
\text { tiva. Entrevistas } \\
\text { semiestruturadas. }\end{array}$ & $\begin{array}{l}\text { Verificou-se que o adoecimento psíqui- } \\
\text { co feminino mantém estreita correla- } \\
\text { ção com a violência contra as mulheres } \\
\text { e a repressão sexual ainda vigente na } \\
\text { sociedade. No que tange à vivência } \\
\text { do adoecimento psíquico masculino, } \\
\text { requer enfrentar a questão do estigma. } \\
\text { Faz-se necessário reforçar a impor- } \\
\text { tância e urgência de se estabelecer } \\
\text { uma discussão interdisciplinar sobre } \\
\text { a doença mental e a sociedade, sendo } \\
\text { de suma importância a contribuição } \\
\text { sociológica sobre o tema. }\end{array}$ \\
\hline
\end{tabular}




\begin{tabular}{|c|c|c|c|c|c|}
\hline D & $\begin{array}{l}\text { Condições de vida, } \\
\text { gênero e saúde } \\
\text { mental das traba- } \\
\text { lhadoras rurais } \\
\text { assentadas. } \\
\text { Estudos de } \\
\text { Psicologia, } 2014 \text {. }\end{array}$ & $\begin{array}{l}\text { DIMENSTEIN, M. } \\
\text { D. B.; LEITE, J. F. }\end{array}$ & $\begin{array}{l}\text { Investigar a preva- } \\
\text { lência de Transtor- } \\
\text { nos mentais comuns } \\
\text { e os possíveis } \\
\text { fatores relacionados } \\
\text { à emergência de tais } \\
\text { transtornos entre } \\
\text { mulheres. }\end{array}$ & $\begin{array}{l}\text { Pesquisa de caráter } \\
\text { quantitativo e } \\
\text { qualitativo de } \\
\text { inspiração } \\
\text { etnográfica. }\end{array}$ & $\begin{array}{l}\text { Os resultados apontam para a alta } \\
\text { prevalência de TMC }(43,6 \%) \text { entre as } \\
\text { assentadas e sugerem a articulação } \\
\text { entre pobreza, violência de gênero, } \\
\text { sobrecarga laboral e a ocorrência de } \\
\text { TMC. }\end{array}$ \\
\hline $\mathbf{E}$ & $\begin{array}{l}\text { Depressão entre } \\
\text { mulheres da } \\
\text { periferia de } \\
\text { São Paulo. } \\
\text { Revista Saúde } \\
\text { Pública, } 2007\end{array}$ & $\begin{array}{l}\text { MARTIN, D.; } \\
\text { QUIRINO, J.; } \\
\text { MARI, J. }\end{array}$ & $\begin{array}{l}\text { Analisar o signifi- } \\
\text { cado da depressão } \\
\text { para mulheres } \\
\text { diagnosticadas } \\
\text { com o transtorno } \\
\text { e o contexto do } \\
\text { atendimento. }\end{array}$ & $\begin{array}{l}\text { Estudo qualitativo. } \\
\text { Observação } \\
\text { etnográfica e } \\
\text { entrevistas em } \\
\text { profundidade. } \\
\text { A interpretação } \\
\text { dos resultados } \\
\text { baseou-se no } \\
\text { conceito de cultura. }\end{array}$ & $\begin{array}{l}\text { As entrevistadas tinham ampla noção } \\
\text { do transtorno, aceitando o tratamento } \\
\text { com medicação. Todas as entrevista- } \\
\text { das identificaram a origem da doença } \\
\text { em eventos passados, como: morte de } \\
\text { filho, episódios violentos ligados ao } \\
\text { tráfico de drogas, desemprego e agres- } \\
\text { sividade do companheiro. A violência } \\
\text { era comum no cotidiano das entrevis- } \\
\text { tadas, tanto fora como dentro de casa. }\end{array}$ \\
\hline $\mathbf{F}$ & $\begin{array}{l}\text { Não é uma rede } \\
\text { que flui - da } \\
\text { invisibilidade às } \\
\text { possibilidades de } \\
\text { novos modos de } \\
\text { cuidar: a violência } \\
\text { contra as mulheres } \\
\text { na saúde mental. } \\
\text { Barbarói, } 2015 \text {. }\end{array}$ & $\begin{array}{l}\text { MEINHARDT, Y. } \\
\text { M.; MAIA, G. F. }\end{array}$ & $\begin{array}{l}\text { Pensar a violência } \\
\text { contra as mulheres } \\
\text { no campo da saúde } \\
\text { e as possibilidades } \\
\text { de promoção de } \\
\text { saúde e cidadania } \\
\text { que o cuidado em } \\
\text { saúde mental pode } \\
\text { proporcionar. }\end{array}$ & $\begin{array}{l}\text { Observação } \\
\text { participante }\end{array}$ & $\begin{array}{l}\text { Observamos que as discussões de gê- } \\
\text { nero, conforme a perspectiva feminista, } \\
\text { se faz necessária nos serviços de saúde } \\
\text { mental, dada a importância da trans- } \\
\text { versalidade de gênero nas políticas } \\
\text { públicas e a visibilidade do tema no } \\
\text { campo da saúde. Ainda há invisibili- } \\
\text { dade e silenciamentos em relação ao } \\
\text { tema, por isso, consideramos que a } \\
\text { inserção dessa discussão possibilitará } \\
\text { promovermos tanto a saúde quanto } \\
\text { a cidadania que o cuidado em saúde } \\
\text { mental pode proporcionar. }\end{array}$ \\
\hline $\mathbf{G}$ & $\begin{array}{l}\text { Relação entre } \\
\text { suporte familiar, } \\
\text { saúde mental e } \\
\text { comportamentos de } \\
\text { risco em estudantes } \\
\text { universitários. } \\
\text { Acta Colombiana } \\
\text { de Psicologia, 2010. }\end{array}$ & $\begin{array}{l}\text { SOUZA, M.S.; } \\
\text { BAPTISTA, A. S. } \\
\text { D.; BAPTISTA, } \\
\text { M. N. }\end{array}$ & $\begin{array}{l}\text { Avaliar à relação } \\
\text { entre suporte fami- } \\
\text { liar, saúde mental e } \\
\text { comportamentos de } \\
\text { risco. }\end{array}$ & $\begin{array}{l}\text { Inventário de } \\
\text { Percepção de } \\
\text { Suporte Familiar } \\
\text { (IPSF), o Self } \\
\text { Reporting } \\
\text { Questionnaire } \\
\text { (SRQ-20) e um } \\
\text { Questionário de } \\
\text { Identificação dos } \\
\text { Comportamentos } \\
\text { dos Estudantes } \\
\text { (QICE). }\end{array}$ & $\begin{array}{l}\text { O cuidado com a saúde mental poderá } \\
\text { aumentar as chances de uma percep- } \\
\text { ção mais adequada sobre o suporte fa- } \\
\text { miliar, ampliando os relacionamentos } \\
\text { saudáveis no cerne do sistema familiar. } \\
\text { Estudos futuros podem abordar outras } \\
\text { variáveis de interesse ligadas ao supor- } \\
\text { te familiar, saúde mental e comporta- } \\
\text { mentos de risco. }\end{array}$ \\
\hline $\mathbf{H}$ & $\begin{array}{l}\text { Saúde Mental, } \\
\text { gênero e violência } \\
\text { estrutural. } \\
\text { Revista bioética, } \\
2012 \text {. }\end{array}$ & $\begin{array}{l}\text { ZANELLO, V.; } \\
\text { SILVA, R. M. C. }\end{array}$ & $\begin{array}{l}\text { Levantar sintomas } \\
\text { e diagnósticos, bem } \\
\text { como as condições } \\
\text { sociais de pacientes } \\
\text { homens e mulheres, } \\
\text { usuários do serviço } \\
\text { de saúde mental no } \\
\text { Distrito Federal. }\end{array}$ & $\begin{array}{l}\text { Analise documental } \\
\text { De prontuários de } \\
\text { pacientes de dois } \\
\text { grandes hospitais } \\
\text { de referência- }\end{array}$ & $\begin{array}{l}\text { Faz-se necessário repensar nossas } \\
\text { práticas e reformular o conceito de } \\
\text { intervenção, pois os determinantes } \\
\text { sociais da doença mental apontam para } \\
\text { desafios específicos para a formulação } \\
\text { de políticas públicas de saúde - para } \\
\text { que façamos, sob a égide de uma su- } \\
\text { posta ciência, nova forma de violência. }\end{array}$ \\
\hline
\end{tabular}




\begin{tabular}{|c|c|c|c|c|c|}
\hline I & $\begin{array}{l}\text { Violência contra a } \\
\text { Mulher e Atendi- } \\
\text { mento Psicológico: } \\
\text { o que Pensam os/as } \\
\text { Gestores/as Muni- } \\
\text { cipais do SUS. } \\
\text { Psicologia ciência e } \\
\text { profissão, } 2006 \text {. }\end{array}$ & PORTO, M. & $\begin{array}{l}\text { Apresentar o que } \\
\text { pensam os/as } \\
\text { gestores/as } \\
\text { municipais do } \\
\text { Sistema Único } \\
\text { de Saúde - SUS - } \\
\text { sobre o atendimen- } \\
\text { to psicológico às } \\
\text { mulheres em situa- } \\
\text { ção de violência. }\end{array}$ & $\begin{array}{l}\text { Investigar o que } \\
\text { pensam gestores/as } \\
\text { de Secretarias } \\
\text { Municipais de } \\
\text { Saúde acerca da } \\
\text { saúde da mulher } \\
\text { em situação de } \\
\text { violência. }\end{array}$ & $\begin{array}{l}\text { Como resultado, pode-se destacar que } \\
\text { existe uma necessidade, percebida } \\
\text { pelos/as gestores/as, do trabalho de } \\
\text { psicólogas/os no contexto da violência } \\
\text { contra a mulher. }\end{array}$ \\
\hline $\mathbf{J}$ & $\begin{array}{l}\text { Violência contra } \\
\text { a mulher, coesão } \\
\text { familiar e drogas. } \\
\text { Revista de Saúde } \\
\text { Pública, } 2007 .\end{array}$ & $\begin{array}{l}\text { RABELLO, P. M.; } \\
\text { CALMAS, A. F. }\end{array}$ & $\begin{array}{l}\text { Avaliar a associa- } \\
\text { ção entre coesão, } \\
\text { adaptabilidade e } \\
\text { risco mental fami- } \\
\text { liar com violência } \\
\text { física contra a } \\
\text { mulher e uso de } \\
\text { drogas. }\end{array}$ & $\begin{array}{l}\text { Estudo tipo caso- } \\
\text {-controle pareado. } \\
\text { A coesão, a } \\
\text { adaptabilidade } \\
\text { e o risco mental } \\
\text { foram avaliados } \\
\text { pela escala Family } \\
\text { Adaptability and } \\
\text { Cohesion Evalua- } \\
\text { tion Scales. Na } \\
\text { análise estatística, } \\
\text { foram utilizados os } \\
\text { testes qui-quadrado } \\
\text { e Exato de Fisher. }\end{array}$ & $\begin{array}{l}\text { O desequilíbrio pela falta de união } \\
\text { entre a família e o uso de drogas altera } \\
\text { decisivamente no funcionamento } \\
\text { familiar, podendo gerar conflitos e } \\
\text { agressões domésticas. }\end{array}$ \\
\hline $\mathbf{K}$ & $\begin{array}{l}\text { Violência contra a } \\
\text { mulher: sofrimento } \\
\text { psíquico e adoeci- } \\
\text { mento mental. } \\
\text { Revista Rene, } 2007 .\end{array}$ & $\begin{array}{l}\text { OLIVEIRA, E. N.; } \\
\text { JORGE, M. S. B. }\end{array}$ & $\begin{array}{l}\text { Refletir sobre a } \\
\text { relação existente } \\
\text { entre violência } \\
\text { contra a mulher, } \\
\text { surgimento do es- } \\
\text { tresse, sofrimento } \\
\text { psíquico e adoeci- } \\
\text { mento mental. }\end{array}$ & $\begin{array}{l}\text { Revisão } \\
\text { Bibliográfica }\end{array}$ & $\begin{array}{l}\text { Milhares de mulheres estão adoecendo } \\
\text { silenciosamente, sem que haja identi- } \\
\text { ficação, abordagem e acolhimento de } \\
\text { seus problemas. }\end{array}$ \\
\hline $\mathbf{L}$ & $\begin{array}{l}\text { Violência por } \\
\text { parceiro íntimo na } \\
\text { gestação: identifi- } \\
\text { cação de mulheres } \\
\text { vítimas de seus } \\
\text { parceiros. } \\
\text { Revista Gaúcha de } \\
\text { Enfermagem, } 2015 .\end{array}$ & $\begin{array}{l}\text { OLIVEIRA, L. } \\
\text { C. Q.; MACHA- } \\
\text { DO, M. de O. F.; } \\
\text { STEFANELLO, J.; } \\
\text { SPONHOLZ, F. A. }\end{array}$ & $\begin{array}{l}\text { Identificar, entre as } \\
\text { usuárias de um ser- } \\
\text { viço de atendimento } \\
\text { pré-natal, mulheres } \\
\text { em situação de vio- } \\
\text { lência por parceiro } \\
\text { íntimo durante a } \\
\text { gestação atual. }\end{array}$ & $\begin{array}{l}\text { Estudo observa- } \\
\text { cional, transversal. } \\
\text { Análise univariada, } \\
\text { distribuição de fre- } \\
\text { quências, medidas } \\
\text { de tendência cen- } \\
\text { tral e variabilidade, } \\
\text { e testes qui-quadra- } \\
\text { do et de Student. }\end{array}$ & $\begin{array}{l}\text { Houve alta prevalência de violência } \\
\text { sexual entre as grávidas dos serviços } \\
\text { de saúde avaliados. Mulheres com an- } \\
\text { tecedente de violência sexual apresen- } \\
\text { taram pior percepção de saúde do que } \\
\text { as sem antecedente. }\end{array}$ \\
\hline M & $\begin{array}{l}\text { Violência sexual e } \\
\text { associação com a } \\
\text { percepção indivi- } \\
\text { dual de saúde entre } \\
\text { mulheres gestantes. } \\
\text { Revista de Saúde } \\
\text { Pública, } 2009 .\end{array}$ & $\begin{array}{l}\text { AQUINO, N. M. } \\
\text { R.; SUN, S. Y.; } \\
\text { OLIVEIRA, E. M.; } \\
\text { MARTINS, M. da } \\
\text { G.; SILVA, J. F.; } \\
\text { MATTAR, R. }\end{array}$ & $\begin{array}{l}\text { Estimar a preva- } \\
\text { lência de histórico } \\
\text { de violência sexual } \\
\text { entre mulheres } \\
\text { gestantes e sua } \\
\text { associação com a } \\
\text { percepção de saúde. }\end{array}$ & $\begin{array}{l}\text { Estudo transversal. } \\
\text { Os instrumentos uti- } \\
\text { lizados: inventário } \\
\text { de violência sexual, } \\
\text { inventário de dados } \\
\text { sociodemográficos } \\
\text { e questionário de } \\
\text { qualidade de vida } \\
\text { relacionada à saúde. }\end{array}$ & $\begin{array}{l}\text { Houve alta prevalência de violência se- } \\
\text { xual entre as grávidas dos serviços de } \\
\text { saúde avaliados. Mulheres com antece- } \\
\text { dente de violência sexual apresentaram } \\
\text { pior percepção de saúde do que as sem } \\
\text { esse antecedente. }\end{array}$ \\
\hline
\end{tabular}


Através da leitura dos 13 artigos selecionados para análise levantamos algumas categorias, sendo essas: áreas dos pesquisadores/autores; profissionais envolvidos no cuidado; agressor; serviços de atendimento às vítimas; políticas públicas e leis.

$\mathrm{Na}$ categoria áreas dos pesquisadores/autores tivemos como base as áreas descritas pelo $\mathrm{CNPq}$, a fim de padronizar tais categorias. A maioria dos artigos publicados foram de pesquisadores/autores das Ciências Humanas (C, D, I, F, G, H e M) e Ciências da Saúde (A, B, E, J, K, L e M), contabilizando 7 artigos cada e um artigo com profissionais das Ciências Exatas (B).

Nas Ciências Humanas foram contabilizados 5 artigos em que os pesquisadores/autores eram da Psicologia (D, I, F, G e H), 2 das Ciências Sociais (C e M) e 1 da História (H). Nas Ciências da Saúde constou com 4 artigos de pesquisadores da Enfermagem (A, B, K e L), 2 da Medicina (E, M), 1 da Odontologia (J) e 1 da Fisioterapia (B). Das Ciências Exatas tivemos no artigo B profissionais da Engenharia Mecânica, de Alimentos e Estatística.

A categoria de profissionais envolvidos nos atendimentos às vítimas de violência teve 2 artigos que referenciaram o profissional enfermeiro (A e F), o psicólogo em 3 artigos (E, F e I), e o profissional mais citado foi o médico, em 7 artigos (D, E, F, H, K, L e M). A equipe multiprofissional é mencionada em 4 artigos (F, I, K e M), contudo, somente em um é descrita (F). E 4 artigos não assinalam nenhum profissional (B, C, G e J).

Outra categoria analisada foi a categoria agressor. Os agressores mais mencionados nos artigos foram "companheiro", "marido" ou "parceiro", contabilizando 10 artigos (A, B, D, E, F, I, J, K, L e M). Os segundos agressores mais citados foram "ex-companheiro", "ex-parceiro" ou "ex-cônjuge”, referidos em 6 artigos (B, C, D, I, J e L). Somente dois artigos não identificaram o agressor (artigo G e H). Um artigo indica o pai, padrasto e outro familiar (I). Apenas um artigo aponta desconhecido como agressor (M).

O serviço de atendimento às mulheres vítimas de violência mais recorrente nos artigos foi a delegacia de polícia (A, B, F, I, J, K, L e M), sendo indicada em 8 artigos. O segundo serviço mais referido foi o Centro de Assistência Psicossocial (CAPS), mencionado em 3 artigos (C, F e K). Os serviços hospital (C e D) e hospital psiquiátrico (C e H) são identificados em 2 artigos. Somente um artigo aponta a Unidade Básica de Saúde (UBS) (E), o Centro de Referência Especializada de Assistência Social (CREAS) (F) e o ambulatório destinado ao atendimento a gestantes (L).

Na categoria políticas públicas e leis, os artigos apresentaram a Lei do Feminicídio, o Código Penal (1940) e o Programa Nacional de Combate à Violência Contra a Mulher em apenas um dos artigos (F). O Programa de Atenção Integral à Saúde da Mulher (I) e o Programa Bolsa Família (D) também apareceram em um artigo. A Lei Maria da Penha foi insignificantemente citada em dois artigos (D e F). Quatro artigos não apontaram nenhuma política pública ou lei (A, E, J e L) e, cinco artigos falaram sobre as políticas públicas, mas não delimitaram quais (B, C, G, H e K). A seguir realiza-se a análise e discussão dos resultados obtidos na pesquisa. 
ANÁLISE E DISCUSSÃO

\section{HEGEMONIA MÉDICA}

Analisando as categorias: áreas dos pesquisadores/autores e a dos profissionais envolvidos no atendimento às mulheres vítimas de violência, percebemos discrepância em relação as áreas. Pois, a primeira categoria apresenta somente 2 artigos (E e M) com pesquisadores/autores da área médica e a segunda categoria destacou o médico como profissional mais mencionado nos artigos, sendo citado em 7 artigos (D, E, F, H, K, L e M).

Os artigos D, E e H apontam a hegemonia médica, destacando: a medicalização do social, ou seja, da pobreza e das mazelas sociais; o tratamento centrado no modelo biomédico, reduzindo o social e o mental ao cerebral e físico, evidenciando o médico como detentor do saber. Os artigos M e K referenciam a equipe de saúde, mas o único profissional declarado é o médico.

Esses resultados nos remetem ao Projeto de Lei 25/2002, popularmente conhecido como Ato Médico. O projeto de lei estabelece quais os procedimentos serão exclusivos aos médicos, quais serão compartilhados com outros profissionais da saúde e quais serão restritos a esses outros profissionais. O Ato Médico assume uma disputa entre profissionais da saúde pela hegemonia e controle do mercado de trabalho (ACIOLE, 2006).

Dessa forma, podemos perceber a fragmentação do cuidado, centrado ainda no modelo biomédico, desconsiderando a subjetividade dessas mulheres que sofreram violência, desvalorizando a equipe multiprofissional e, assim, negligenciando o cuidado integral. Por conseguinte, para que o cuidado seja efetivo, devemos validar a experiência da mulher vítima de violência, compreendendo a dimensão dessa problemática, executando interlocução dos serviços de saúde, assistenciais e de segurança de forma horizontal.

\section{“EM BRIGA DE HOMEM E MULHER, POR FAVOR, METAM A COLHER"}

A categoria agressor apontou que os agressores mais recorrentes nos artigos foram: "companheiro", "marido" ou "parceiro", contabilizando 10 artigos (artigo A. B, D, E, F, I, J, K, L e M). Em segundo lugar, os agressores mais evidenciados foram os "ex-companheiro", "ex-parceiro" ou “ex-cônjuge” (artigos B, C, D, I, J e L), referidos em 6 artigos.

De acordo com Data Senado (2013), em 65\% dos casos as mulheres foram agredidas pelo marido, companheiro ou namorado. Menos frequente, mas ainda significativo, os ex-namorados, ex-maridos e ex-companheiros também aparecem como agressores em 13\% dos casos.

Logo, é comum a violência contra as mulheres ser perpetrada por conhecidos. Historicamente esse tipo de violência foi legalmente aceita e por muito tempo tolerada. A primeira Constituição 
Brasileira, em 1824, excluía as mulheres de praticar todos os atos da vida civil. O Código Civil de 1916 considerava as mulheres "relativamente incapazes", sendo o homem chefe da sociedade conjugal. Como exemplo, o Art. 178 previa, em dez dias, contados do casamento, a ação do marido para anular o matrimônio contraído com a mulher já deflorada, ou seja, aquela que não possuía mais a virgindade.

Assim, como no Código Civil de 1916, o judaísmo declarava através dos textos bíblicos proibições às mulheres, tais como: “se a mulher trair o seu marido, ela será feita em objeto de maldição pelo Senhor..."; "se uma jovem é dada por esposa a um homem e este descobre que ela não é virgem, então será levada para a entrada da casa de seu pai e a apedrejarão até a morte” (LIMA, 2010, p.4).

A violência conjugal também foi legitimada no Código Penal, o Art. 108 extinguia a penalidade pelo casamento, do agente com a vítima, nos crimes contra os costumes (BRASIL, 1940). Ou seja, o homem que estuprasse uma mulher com a qual ele fosse casado não era considerado crime de estupro. Contudo, se as leis mudaram, os costumes não mudaram, do ano de 2007 a 2013 as taxas de feminicídio aumentaram significativamente, passando de 3,9 para 4,8 por 100 mil, representando um aumento de 23,1\% (WAISELFISZ, 2015).

\section{SERVIÇOS DE SAÚDE, POLÍTICAS PÚBLICAS E LEIS}

Os resultados apontam que o serviço de atendimento às mulheres vítimas de violência mais citado nos artigos analisados foi a Delegacia de Polícia (A, B, F, I, J, K, L e M). A Delegacia de Polícia é fundamental, pois auxilia na segurança das mulheres vítimas de violência, tentando minimizar sua reincidência. Contudo, não é um serviço destinado ao cuidado, mas sim ao amparo das vítimas explicando e defendendo seus direitos, estimulando as denúncias das agressões e realizando os encaminhamentos necessários.

Um dos descritores para procura dos artigos foi "saúde mental", todavia, os únicos serviços especializados no atendimento de saúde mental apontados foram o CAPS (C, F e K) e o Hospital Psiquiátrico (C e H). Outro descritor utilizado foi "violência", isso posto, o CREAS foi meramente manifestado em um artigo $(\mathrm{F})$, sendo um serviço especializado no atendimento às vítimas de violência.

Outros serviços de saúde pouco assinalados foram o hospital geral, a UBS e o ambulatório de atendimento às gestantes. Assim, somando todos os artigos que citam serviços de saúde e de saúde mental contabilizamos 7 (C, D, E, F, H, K e L) e somente um artigo refere-se a serviços de assistência social (F).

Nesse sentido, os serviços envolvidos no cuidado, as políticas públicas e leis também foram pouco exploradas. As leis e programas específicos de enfrentamento à violência contra as mulheres foram irrisoriamente indicados, sendo a Lei Maria da Penha citada em dois artigos (D e F) e, a Lei de Feminicídio (F) e o Programa de Atenção Integral à Saúde da Mulher (I) em apenas um. Artigos que não revelaram nenhuma lei ou política pública foram quatro (A, E, J e L) e cinco mencionaram as políticas públicas, mas não as delimitaram (B, C, G, H e K). 
De acordo com PNAISM, no Brasil, durante o século XX, surgiram as primeiras políticas nacionais de saúde das mulheres, porém, essas políticas eram limitadas às demandas relativas à gravidez e ao parto. Nesse período, os programas materno-infantis evidenciavam a visão restrita sobre as mulheres, de mãe, doméstica e cuidadora (BRASIL, 2004).

Diante dessa conjuntura, o movimento de mulheres e feministas se posicionou contrário à perspectiva reducionista de como as mulheres eram tratadas. Devido à desigualdades entre os sexos, as necessidades relacionadas à sexualidade, à anticoncepção e à prevenção de doenças eram totalmente negligenciadas (BRASIL, 2004).

O Plano Nacional de Políticas para as Mulheres é um compromisso assumido pelo governo desde 2002, para enfrentar as desigualdades de gênero. Refere-se à formulação, coordenação e articulação de políticas que promovam a igualdade entre homens e mulheres (BRASIL, 2005). As mulheres e feministas alcançaram diversas conquistas desde então, leis importantes como a Lei Maria da Penha (2006) e a Lei do Feminicídio (2015), além da implantação de inúmeros programas e políticas públicas, que interferiram no seu atendimento à saúde, tais como o atendimento humanizado na rede do Sistema Único de Saúde.

Contudo, o número de mulheres vítimas de violência ainda é significativamente alto, pois a violência contra mulheres é estrutural em nossa sociedade, herança de uma sociedade patriarcal, machista, sexista e misógina. Portanto, as questões de desigualdade de gênero devem ser consideradas na formulação de políticas públicas, uma vez que há padrões distintos de comportamentos aceitáveis socialmente para homens e mulheres, estando expostos a padrões diferentes de sofrimento, adoecimento e morte.

\section{CONSIDERAÇÕES FINAIS}

A presente pesquisa possibilitou identificar, mediante análise das publicações científicas selecionadas, a dificuldade enfrentada, ainda hoje, em relação ao trabalho multiprofissional com mulheres vítimas de violência. O cuidado dessas mulheres muitas vezes é limitado ao fisiológico e à medicalização do sofrimento, seguindo uma hegemonia médica. Para que haja um cuidado integral de qualidade é fundamental identificar, através de uma escuta qualificada e sensível, as demandas daquela mulher, considerando a vulnerabilidade do contexto em que está inserida.

Seguindo a perspectiva do cuidado, além do atendimento multiprofissional, é essencial articular os serviços de diferentes modalidades, tanto da saúde, como da assistência e segurança, a fim de garantir que tenham acesso às políticas públicas destinadas às vítimas de violência. As políticas públicas também estipulam ações de prevenção, as quais devem ser executadas por profissionais junto à população.

Para a formulação de políticas públicas, as questões de desigualdades de gênero devem ser consideradas, uma vez que há padrões distintos impostos socialmente de comportamentos aceitáveis 
para homens e mulheres, estando expostos a padrões diferentes de sofrimento, adoecimento e morte. Portanto, foi averiguado que os agressores têm vínculo afetivo com as mulheres vítimas, logo, é preciso que haja mais ações de políticas públicas destinadas aos agressores, visando a prevenção de reincidência desse tipo de violência.

\section{REFERÊNCIAS}

ACIOLE, Giovanni Gurgel. A Lei do Ato Médico: Notas sobre Suas Influências para a Educação Médica. Revista: Brasileira de Educação Médica, Rio de Janeiro, v. 30, n. 1, p. 47-54, jan./abr. 2006.

BRASIL. Lei no 3.071 de $1^{0}$ de janeiro de 1916. Aprova o Código Civil. Disponível em: https://bit.ly/ 314yVcI. Acesso em: 28 ago. 2018.

. Constituição (1998). Constituição da República Federativa do Brasil. Alexandre de Morais (org). 16. ed. São Paulo: Atlas, 2000.

Constituição (1824). Constituição Política do Império do Brasil. Rio de Janeiro, 1824. Disponível em: https://bit.ly/3kYVXSb. Acesso em 30 ago. 2018.

. Lei n.⒒340, de 7 de Agosto de 2006. Lei Maria da Penha. Disponível em: https://bit.ly/ 375EhiV. Acesso em: 05 set. 2018.

Lei $\mathbf{n}^{\mathbf{0} 13.104}$, de 9 de Março de 2015. Altera o art. 121 do Decreto-Lei $\mathrm{n}^{\circ} 2.848$, de 7 de dezembro de 1940 - Código Penal, para prever o feminicídio como circunstância qualificadora do crime de homicídio, e o art. $1^{\circ}$ da Lei $\mathrm{n}^{\circ} 8.072$, de 25 de julho de 1990, para incluir o feminicídio no rol dos crimes hediondos. Disponível em: https://bit.ly/3nU8xUF. Acesso em: 05 set. 2018.

Decreto-Lei 2.848, de 07 de dezembro de 1940. Código Penal. Diário Oficial da União, Rio de Janeiro, 31 dez. 1940.

Secretaria especial de políticas para as mulheres. Plano Nacional de Políticas para as Mulheres. Disponível em: https://bit.ly/2J4tcGt. Acesso em: 28 ago. 2018.

. Ministério da Saúde. Secretaria de Atenção à Saúde. Departamento de Ações Programáticas Estratégicas. Política nacional de atenção integral à saúde da mulher: plano de ação 2004-2007. Brasília: Ministério da Saúde; 2004. 

. Senado Federal. Violência doméstica e familiar contra a mulher. Secretaria de transparência,

DataSenado, março de 2013.

Conselho Federal de Medicina. Ato Médico. Disponível em: https://bit.ly/36YmD0s. Acesso em: 30 ago. 2018.

LIMA, Rita de Lourdes de. O Imaginário Judaico-Cristão e a Submissão das Mulheres. Fazendo Gênero, v. 9, Diáspora, Diversidade, Deslocamentos. 23 a 26 de agosto, 2010.

MENDES, Karina Dal Sasso; SILVEIRA, Renata Cristina de Campos Pereira, GALVÃO, Cristina Maria. Revisão integrativa: método de pesquisa para a Incorporação de evidências na saúde e na enfermagem. Revista: Texto Contexto Enfermagem, Florianópolis, v. 4, n. 17, p. 758-764, out./dez. 2008.

WAISELFISZ, Julio, Jacobo. Mapa da violência 2015 homicídio de mulheres no Brasil. 1. ed., Brasília - DF - 2015. Disponível em: www.mapadaviolencia.org.br. Acesso em: 30 de ago. 2018. 
